\title{
FAMÍLIA, ABUSO E DEPENDÊNCIA DE DROGAS DESAFIOS CLÍNICOS E DAS PESQUISAS
}

\author{
Eroy Aparecida da Silva \\ Psicoterapeuta Familiar e Comunitária, Doutora em Ciências e Pesquisadora na Área de \\ Álcool e Outras Drogas Unidade de Dependência de Drogas-UDED-Disciplina Medicina e \\ Sociologia do Uso de Drogas-Departamento de Psicobiologia, Universidade Federal de São \\ Paulo -UNIFESP \\ e-mail: eroyntc@gmail.com
}

\section{Resumo}

A família é sistema aberto que apresenta uma dinâmica variável dependendo do contexto sociocultural onde está inserida. É considerada um modelo básico de constituição de uma pessoa, e atualmente apresenta conceitos amplos. O funcionamento intrafamiliar está em constante troca como o meio ambiente e social. Desta maneira repercussões interfamiliares impactam as famílias e vice versa. Este texto abordará de forma sucinta especificamente alguns desafios da família contemporânea diante do abuso e dependência de drogas ressaltando a importância do investimento em pesquisas e a construção de políticas públicas voltadas para todo sistema familiar.

Palavras Chave: família, dependência de drogas, tratamento, pesquisa

\section{Breve História da Família}

A história da família ocidental é antiga e passou por importantes transformações com o passar dos séculos. Suas definições são variadas, o que lhe garante atualmente amplos e diversos conceitos, envolvendo aspectos demográficos, afetivos, vínculos de afinidade e ou consangüíneo transmissão valores e de bens dentre outros ${ }^{1}$. Atualmente é definida

\section{Referência:}

Silva, Eroy Aparecida da. Família, Abuso e Dependência de Drogas Desafios Clínicos e das Pesquisas. In: Anais da V Jornada de Psicologia no Hospital Municipal do Campo Limpo [= Blucher Medical Proceedings, vol.1, num.6]. São Paulo: Editora Blucher, 2015.

DOI $10.5151 /$ medpro-5jphmcl-001 
como um sistema vivo, com regras, costumes, afetos, envolvimento em constante relação com o meio social. O sistema familiar é considerado ainda um modelo básico de socialização das pessoas e que está para além dos vínculos sanguíneos, envolvendo principalmente vínculos de afinidades e pertença ${ }^{2,3,4}$

A família tem um funcionamento dinâmico, constroem valores, legados e expressividade afetiva através da história de várias gerações (transgeracionais). ${ }^{5}$ A partir dos anos de 1960, passou por várias mudanças tanto socioculturais, psicológicas e emocionais importantes. A inserção da mulher, no mercado de trabalho, o advento da pílula anticoncepcional, a diminuição do número de filhos, a valorização da criança como um ser de direito, os movimentos políticos e a contra cultura influenciaram diretamente a constituição da família modificando assim as relações de poder entre os sexos de uma forma mais igualitária entre os papéis e tarefas do homem e da mulher; embora ainda hoje prevaleçam "resquícios culturais" da supremacia do sexo masculino sobre o feminino, mas que apontam já uma mudança significativa para um maior equilíbrio entre os gêneros.

\section{Desafios da família contemporânea}

Novos valores sociais e culturais, a globalização, a revolução tecnológica trouxeram para a família atual muito desafios: o enfrentamento da à violência urbana, o desemprego, doenças sexualmente transmissíveis como a contaminação do vírus HIV, alterações abruptas no ecossistema, uso e abuso de drogas psicotrópicas dentre outros. ${ }^{6,4}$

Pesquisas recentes sobre o funcionamento familiar referem que muitos destes desafios contemporâneos aumentaram o nível de estresse intrafamiliar, repercutindo de forma direta nos vínculos familiares, colaborando para que pessoas utilizassem substâncias psicoativas de forma abusiva com diferentes funções, no próprio ambiente familiar. $7,6,4$

Embora nem todas as pessoas que usam drogas sejam dependentes, algumas podem começar a viver problemas na escola, no trabalho ou em casa. Estes problemas são variados desde alterações de humor, de qualidade de sono, que comprometem a saúde física até violência intra e interfamiliar causando alterações psíquicas e relacionais. Estudos sobre práticas preventivas envolvendo o grupo familiar apontam que um dos locais mais propícios de observação de pessoas é o núcleo familiar, independente do lugar 
e qualidade dos vínculos ${ }^{8}$. O cuidado, a observação e a percepção adequada das pessoas em casa podem ser capazes de detectar vários problemas em cada um, o contrário também pode acontecer, a falta de atenção e percepção é responsável pelo que vários autores chamaram no passado de "cegueira familiar". 9

Em outras situações é possível constatar que quando uma pessoa começa a ter problema, por exemplo, com o uso exagerado de bebida alcoólica tenha dificuldade de perceber ou em outros casos, embora perceba apresenta dificuldade de mudar seu comportamento.

O uso e abuso de drogas é um tema que em geral preocupa os familiares e as reações destes são variadas ao tratar deste assunto. Existe desde os medos de pais de crianças e jovens que nunca fizeram uso de drogas até sentimentos de raiva, insegurança, estresse e impotência de pais que já convivem com o abuso ou dependência em casa ou ainda os filhos que desde muito cedo já convivem com a dependência de álcool e outras drogas dos pais. São comuns nos depoimentos de pais cujos filhos estão envolvidos no tráfico de drogas, ou cumprindo medidas socioeducativas sentimentos perturbadores de medo, cansaço, culpa. ${ }^{10}$ Neste sentido existem diferentes intervenções para tratar desta questão, pois embora a relação problemática com consumo de drogas traga a todos os membros da família muitos afetos desagradáveis, entretanto este também pode ser um momento de enfrentamento e mudanças significativas para o sistema como um todo, além de uma oportunidade para que novos rearranjos ocorram no que diz respeito aos padrões de comunicações, limites e redefinições de papéis e tarefas no interior da família.

Muitas vezes o cenário imaginário dos pais sobre drogas psicotrópicas, é aquele relacionado às ilegais como: cocaína, crack, maconha, heroína, desconsiderando as legais e de maior consumo como álcool, tabaco, solventes, “calmantes”(ansiolíticos)

Para discutir este assunto de maneira clara é necessário ampliar a nossa compreensão para além da droga em si, observando a pessoa como um todo e o meio em que ela vive e, além disso, lidar com os estigmas e preconceitos que permeiam este tema. Dessa forma, é no ambiente familiar que a prevenção tem início. Preocupações freqüentes dos pais em relação às conseqüências do abuso e da dependência de drogas, principalmente as lícitas, quando devidamente consideradas, podem auxiliar na construção de programas de ações comunitárias visando à prevenção. 


\section{Família, Abuso e Dependência de Drogas: Desafios Clínicos e das Pesquisas}

As intervenções envolvendo o uso, abuso e dependência de drogas, o indivíduo e suas famílias apresentam um espectro amplo desde a prevenção até o tratamento. A orientação preventiva, detecção dos fatores de risco e proteção e a detecção precoce estão voltadas para as práticas de prevenção universal e seletiva, enquanto que os tratamentos são indicados para as pessoas que já desenvolveram dependência.

A droga psicotrópica quando presente na vida de uma pessoa pode afetar todo o ambiente familiar, e muitos estudos atualmente ressaltam a importância da participação dos familiares nos tratamentos dos dependentes. ${ }^{4,8}$

Tratamento está relacionado a um conjunto de procedimentos que envolvem uma equipe clínica básica (psicólogo, assistente social e médico) além de várias intervenções de acordo com a necessidade de cada um: diagnóstico, desintoxico, uso de medicação, psicoterapia familiar e grupal, internações breves dentre outros. Vale reafirmar que. embora a família faça parte da história da humanidade, os cuidados em relação ao sistema como um todo, são recentes. As abordagens familiares com dependentes de drogas iniciaram em meados da década de 1950, nos EUA, enquanto que no Brasil apenas nos $\operatorname{anos} 80$.

A psicoterapia familiar surge nos anos de 1950 nos E.U.A., por um grupo diversificado de investigadores, desenvolveu-se em 1960 e foi amadurecendo na década de 70 em diferentes locais no mundo. O movimento heterogêneo de clínicos e pesquisadores na área de família foi responsável pelo surgimento de várias abordagens familiares, no entanto uma das maiores contribuições nesta área é a da visão sistêmica que enfatizou a importância de se compreender o comportamento dos indivíduos no contexto e em interação. ${ }^{4}$ Até então as pessoas sintomáticas eram atendidas isoladas e separadas de seu grupo familiar. Vale esclarecer que os terapeutas das abordagens individuais reconheciam a importância da família na formação da personalidade, mas partiam do pressuposto que as representações internas dos acontecimentos do passado exerciam influências mais fortes que as interações familiares. Inversamente, os clínicos de família, defendiam que o desenvolvimento da personalidade tem forte influência externa, localizadas no núcleo básico de formação das pessoas: o sistema familiar. Atualmente na área de tratamento de dependentes de drogas existe concordância que as 
pessoas são formadas no contexto social, e qualquer tentativa de tratá-las deve incluir a avaliação de suas famílias. ${ }^{4}$

É importante considerar o contexto no tratamento familiar por dois motivos básicos, dentre os vários outros sugeridos: 1. As pessoas e seus problemas podem ser melhor compreendidas quando seu contexto familiar é considerado e conhecido; 2. Mudanças no contexto familiar promovem transformações nas pessoas e em seus problemas.

A psicoterapia familiar tem em seu arcabouço três pressupostos teóricos importantes: o sistêmico, o cognitivo-comportamental e o psicanalítico. Inicialmente a visão sistêmica e a cognitivo-comportamental se complementaram mais do que a sistêmica e a psicanalítica, no entanto mais recentemente é visível o interesse em integrar a visão psicanalítica e a sistêmica. ${ }^{4}$

Alguns estudos mostram que dependentes de drogas, cujos familiares participam do tratamento apresentam resultados mais encorajadores do que aqueles cuja família não vem para o tratamento 9,11

A Terapia Rede proposta por Copello ${ }^{11,12}$ é uma delas, a premissa desta intervenção enfatiza que uma intervenção efetiva relacionada ao enfrentamento de problemas envolvendo dependência de álcool e outras drogas apresentam maior possiblidade de ser efetivo se for desenvolvida uma rede social de apoio para a mudança incluindo primariamente várias estratégias familiares e posteriormente envolvendo todas as outras redes significativas do dependente.

Outro modelo que apresenta resultados encorajadores é a Terapia Familiar Multimensional (TFM) principalmente para adolescentes abusadores de drogas. ${ }^{13}$ Esta abordagem apresenta quatro domínios interdependentes no tratamento: os pais e outros membros da família, os adolescentes, e outros sistemas interfamiliares importantes, os terapeuta atuam simultaneamente em cada domínio, de acordo com o perfil para adolescente e da família.

No Brasil ainda são escassas propostas de tratamento que atendam os usuários ou dependentes de drogas juntos com suas famílias. Estas datam dos meados da década de 1980, entretanto a maioria das intervenções atuais ainda está voltada mais aos dependentes do que todo sistema familiar. ${ }^{14}$ Isso ocorre por vários motivos, dentre eles as políticas públicas enfatizam o individual e não o sistêmico, repercutindo na cultura das 
famílias que também consideram que apenas o dependente deve ser incluído no tratamento. $^{4}$

Uma proposta básica do tratamento para dependente de drogas deve ter inicio com a avaliação tanto individual quanto familiar do dependente.

A avaliação individual deve envolver exame clínico geral, marcadores biológicos, história da evolução do uso e o diagnóstico do abuso e dependência.

O diagnóstico familiar deve envolver além do dependente o maior numero possível de pessoas do seu sistema familiar, a elaboração do Genograma Familiar ${ }^{15}$, a investigação do uso abusivo do álcool e outras drogas em todo sistema familiar, assim como outras dependências ( obesidade, jogo, compras compulsivas), algum inventário sobre a avaliação familiar também é sugerido.

O tratamento familiar é focado no funcionamento geral da família e nas orientações em relação à prevenção de recaída e mudança de estilo de vida e motivação para o tratamento. Baseado nos diagnósticos individual e familiar é estabelecido o plano de tratamento com sessões que variam de 8 a 24 encontros. Após o término de tratamento a família deve ser contatada ao menos uma vez ao ano para o acompanhamento das mudanças ocorridas ao longo do tempo ou mesmo de possíveis recaídas e reencaminhamento para tratamento novamente caso seja necessário.

Outro aspecto muito importante a ser enfatizado nas abordagens familiares no Brasil é o desenvolvimento de pesquisas com as famílias, pois estas são elementos essências para dar embasamento às práticas baseada em evidências mais do que modelos advindos de outras culturas que podem não ser efetivas quando aplicadas a realidade cultural brasileira. Porém este ainda é um desafio, pois pesquisas amplas com famílias tanto normativas quanto clínicas envolvendo metodologias baseadas na compreensão do contexto socioeconômico cultural brasileiro ainda são incipientes ${ }^{4}$, repercutindo diretamente no campo de da assistência e da pesquisa na área de álcool e outras drogas. As pesquisas com dependentes de drogas e suas famílias podem dar subsídios para a construção de políticas públicas familiares, de maneira que este tema possa ser tratado sem julgamentos valorativos e ou morais, e tanto o usuário quanto sua família possa receber atenção e respeito.

As políticas familiares são práticas comuns nos países europeus, pois ampliam os cuidados em relação à família para além das políticas públicas de assistência, envolvendo 
a participação direta dos nos sistemas familiares na construção de programas voltados para a saúde física, mental e social das famílias. Estão orientadas para a construção de redes de sustentação das relações familiares no decorrer de tempo, fortalecendo as famílias a resgatar sua auto-estima e agir com responsabilidade diante de situações adversas. ${ }^{6,16,17,18}$ Sob esta perspectiva a família é encarada como um sistema ativo, participante e responsável na construção propostas tanto de prevenção como tratamento para uso, abuso e dependência de drogas, ao invés de ser considerada uma mera destinatária passiva de intervenção.

Finalmente, mas não menos importante de ser ressaltado no que diz respeito ao lidar com o tema família e dependência de drogas é a capacitação adequada dos profissionais que acolhem esta população.

A capacitação sistematizada e permanente é fundamental, assim como as supervisões clínicas. Muitas vezes a formação baseada no modelo higieniza/sanitarista faz com os cuida dores desenvolvam um desejo ilimitado de "fazer tudo para família" e não com a família, ficando sujeito a desenvolver a "síndrome do salvador". ${ }^{19}$ Os modelos mais recentes de capacitação baseados na educação permanente enfatizam que as principais tarefas desses profissionais são de facilitadores e colaboradores úteis, sem rotular ou estigmatizar. Além disso, motivar e encorajar o indivíduo dependente de droga e sua a família no resgate ou construção de suas competências.

\section{Referências Bibliográficas:}

1. Hintz, H.C. (2001) Novos tempos, novas famílias? Da modernidade à pós modernidade. Pensando famílias. n. 3, 2001.p.8-19. Disponível em: http://www.domusterapia.com.br/pdf/PF3HelenaHintz.pdf. Acesso em: novembro 2014.

2. Silva,E.A. (2001) Abordagens Familiares. Jornal Brasileiro de Dependência Química, 21 (4), $1,21-24$.

3. Silva,E.A. (2010).Visão Sistêmica sobre a Família: uma breve perspectiva históirca.In: G.Bedoian \& Fender,S.9Eds).Mundo da Família:Conceitos e Manejos do Atencimento (1 ${ }^{\text {a }}$.ed.Vol.I.pp 147-153).São Paulo: Projeto Quixote.

4. Silva,E.A. (2011) Avaliação do Funcionamento de Famílias com dependentes de drogas por meio da Family Assessment Measure-III (FAM-III). Tese (doutorado) Universidade Federal de São Paulo.Escola Paulista de Medicina. Programa de Pós Graduação em Psicobiologia. 
5. Cerveny,C.M.O.(Org.) (2007).Família em Movimento, $1^{\text {a }}$.Edição,são Paulo, Casa do Psicólogo.

6. Sarti, C.2003) A Família e individualidade: um problema moderno. IN: A família contemporânea em debate. São Paulo: Cortez.

7. Silva,E.A.;Noto,A.R.; Formigoni,M.L.O.S. (2007) Death by Drug Overdose: Impacto $n$ Families. Journal Psychoactive Drugs, 39 (3).

8. Silva,E.A.; (2011b). Adolescência, mudanças no ciclo vital familiar uso e abuso de drogas. In: Silva,E.A. \& De Micheli (Eds).Adolescência, Uso e Abuso de Drogas: Uma Visão Integrativa. São Paulo: Editora FAP-UNIFESP.

9. Boutillier, H. (1992)La toxicomanie à l'adolescence. In: Grammer, C. et al. L'adolescence, crise familiale: therapie familiale par phases. Tolouse: Éres, 1992.p. 111-130.

10.Silva,E.A.;DeMicheli,,D.;Camargo,B.M.V.;Buscatti,D.;Asevedo,M.A.;Formigoni,M.L.O. S.; (2006) Drogas na adolescência:temores e reações dos pais. Psicologia,Teoria e Prática,V.8,no.1,São Paulo, 41-54.

11.Copello,A.G.; Templeton,L.; Velleman,R.Family Interventions for Drug and Alcohol Misuse: Is There a Best Practice? Curr Opin Psychiatry. Medscape Today, 19(3):271-276, 2006. Disponível em http://www.medscape.com/viewarticle/528488 Acesso em: 22 de novembro de 2014.

12.Copello, A. \& Orford, J. (2002). Addiction and the family: is it time for services to take notice of the evidence? (Editorial).Society for the Study of Addiction to Alcohol and Other Drug Addictions,97, 1361-1363.

13.Liddle, H. A., Dakof, G. A, Parker, K., Diamond, G. S., Barrett, K. \& Tejeda, M. (2001): "Multidimensional Family Therapy for adolescent drug abuse: Results of a randomized clinical trial" in AM. J. drug alcohol abuse, 27 (4), 651-688.

14.Zemel,M.L.S. (2001). O papel da família na dependência, Revista Imesc, n.3, pp.43-66.

15.Mc Goldrick; Gerson,R.;Petry,S.; Genogramas: avaliação e intervenção familiar.Porto Alegre. Artmed, 2012.

16.Sarti, A.C.;2004 Algumas questões sobre família e políticas sociais.In:Jacque,C.Costa;Costa,L.(orgs.).Família em mudança. São Paulo,Companhia Ilimitada. pp.193-213.

17.Ponciano,E.L.T. Habitando espaços em movimento; indivíduo, família e contexto sóciohistórico.Dissertação (doutorado).Rio de Janeiro: Departamento de Psicologia.PUC.RJ.2004.

18.Petrini, G. Políticas sociais dirigidas à família. In: Borges, A; Castro, M. G. (Orgs.) Família, gênero e gerações: desafios para as políticas sociais. São Paulo: Paulinas, 2010a. p. 207-231. 
19.Barreto AP, Terapia Comunitária passo a passo. Fortaleza: Gráfica LCR; 2008.

Castel,R.;(2004). As armadilhas da exclusão social.In R.Caste;,L.E.W. Wanderley e M.W.;Belfiore:Desigualdade e a questão social (p.17-50).São Paulo,Educ. 